\title{
A challenging case of constrictive pericarditis
}

\author{
T. Tak $•$ M. Jahangir
}

Published online: 26 May 2011

(C) Springer Media / Bohn Stafleu van Loghum 2011

We report the case of a healthy 35-year-old male who was seen by his primary care physician with complaints of general fatigue, shortness of breath, night sweats, and abdominal bloating which had started several weeks prior to his visit. A CT scan of the abdomen demonstrated the presence of gall stones. He was subsequently seen by the surgeons and, shortly thereafter, underwent laparoscopic cholecystectomy for suspected cholecystitis. Two weeks after the procedure he reported no significant change in clinical symptoms. A cardiology consultation was subsequently requested at which time his physical examination revealed a $\mathrm{BP}$ of $120 / 80 \mathrm{mmHg}$, (no pulsus paradoxus), pulse 80 beats/min, elevated jugular venous pressure, and a positive Kussmaul's sign. Auscultation of the heart revealed a regular rate and rhythm with no murmurs or

\section{T. Tak}

Division of Cardiology, Franciscan Skemp Healthcare, Mayo Health System,

La Crosse, WI 54601, USA

\section{Jahangir}

Division of Radiology, Franciscan Skemp Healthcare,

Mayo Health System,

La Crosse, WI 54601, USA

T. Tak $(\bowtie)$

Cardiovascular Diseases, Mayo Clinic,

200 First Street SW,

Rochester, MN 55905, USA

e-mail: tak.tahir@mayo.edu gallops. A 'pericardial knock' was audible. There was no evidence of ascites on abdominal examination and no peripheral lower extremity oedema. The ECG showed sinus rhythm with a ventricular rate of 76 beats $/ \mathrm{min}$. No ST abnormalities were seen. Chest X-ray showed a normal cardiac silhouette with no evidence of congestion. He underwent a transthoracic echocardiogram (TTE) which demonstrated a mildly thickened pericardium, small pericardial effusion, a 'septal bounce', significant respiratory variation of mitral inflow velocities, and a dilated inferior vena cava and hepatic veins (Fig. 1). The constellation of clinical and echocardiographic findings was more suggestive of constrictive pericarditis. Right heart catheterisation was, therefore, not considered necessary. A CT scan of the chest confirmed the mildly thickened pericardium, small pericardial effusion, and a dilated inferior vena cava.

He was initially treated with a course of corticosteroids which had no significant effect on his symptoms or pericardial effusion. He was eventually referred to the cardiothoracic surgery department for a surgical consultation and underwent thoracotomy with pericardectomy without complications. At surgery a significant amount of adhesions were noted extending from the pericardium to epicardium. Surgical pathology revealed non-calcific fibrous thickening of the pericardium ranging from 0.1 to $0.6 \mathrm{~cm}$. No discernible aetiology could be determined.

Constrictive pericarditis often presents with insidious signs and symptoms and is notoriously difficult to 

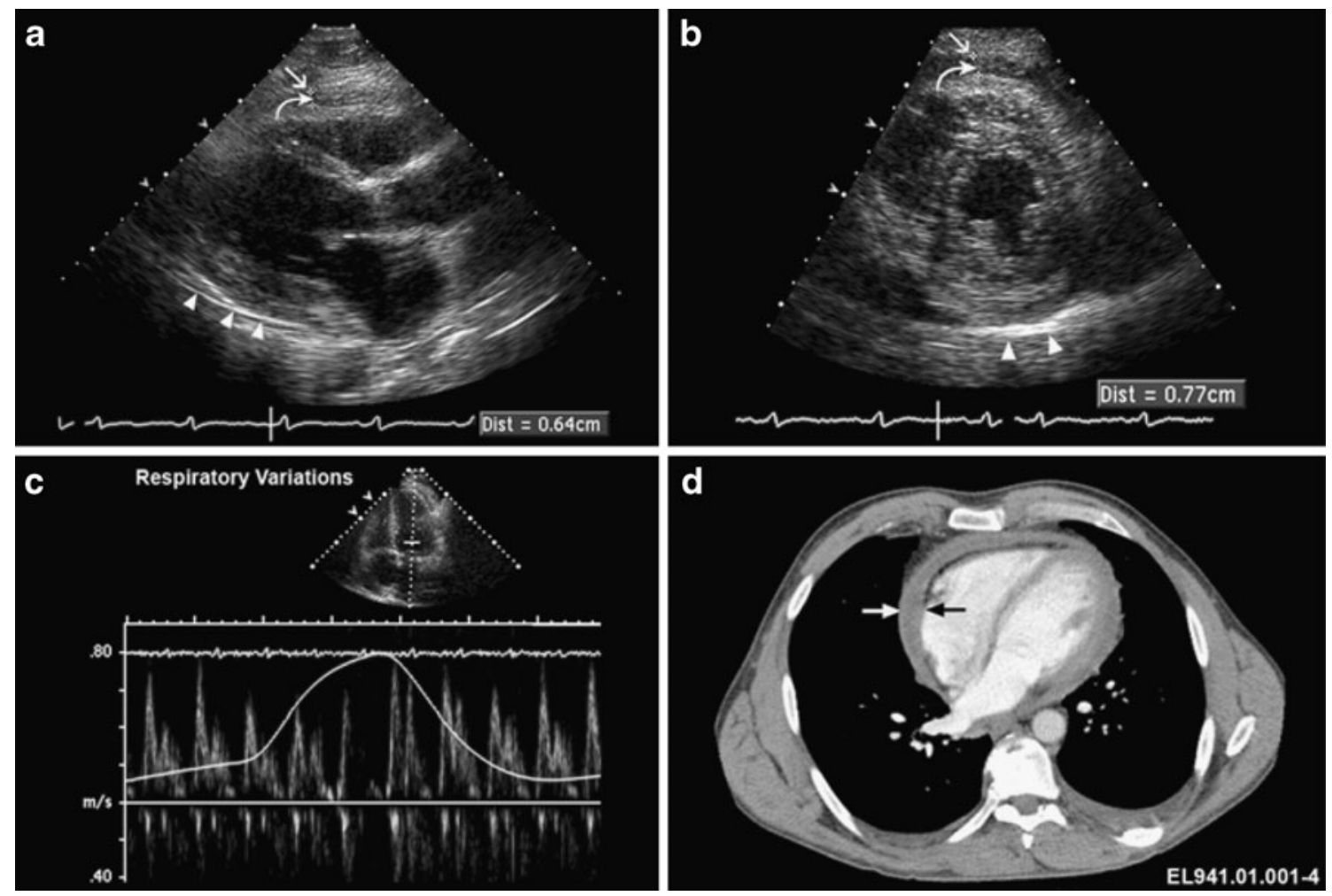

Fig. 1 A composite figure showing a Parasternal long-axis view of the heart; b Short-axis view of heart; c Doppler echocardiography showing significant respiratory variations of mitral inflow velocities; $\mathbf{d}$

CT imaging of the heart. Arrows point to the pericardium and a small amount of pericardial effusion

distinguish from restrictive cardiomyopathy and other abdominal pathology [1]. A detailed history and careful physical examination together with judicious diagnostic imaging usually helps in targeting the correct diagnosis.

Echocardiography, CT imaging, and magnetic resonance imaging have all been used in evaluating patients with constrictive pericarditis [2-4]. A constellation of clinical findings together with classic echocardiographic/Doppler findings should prompt physicians to consider constrictive pericarditis in the differential diagnosis.

\section{References}

1. Johnson KT, Julsrud PR, Johnson D. Constrictive pericarditis at abdominal CT: a commonly overlooked diagnosis. Abdom Imaging. 2008;33(3):349-52.

2. Oh JK, Hatle LK, Seward JB, et al. Diagnostic role of Doppler echocardiography in constrictive pericarditis. J Am Coll Cardiol. 1994;23:151-62.

3. Talreja DR, Edwards WD, Danielson GK, et al. Constrictive pericarditis in 26 patients with histologically normal pericardial thickness. Circulation. 2003;108(15):1852-857.

4. Kim JS, Kim HH, Yoon Y. Imaging of pericardial diseases. Clin Radiol. 2007;62(7):626-31. 